\title{
Empirical model for mean temperature for Indian zone and estimation of precipitable water vapor from ground based GPS measurements
}

\author{
C. Suresh Raju, K. Saha, B. V. Thampi, and K. Parameswaran \\ Space Physics Laboratory, Vikram Sarabhai Space Centre, Thiruvananthapuram 695 022, India
}

Received: 15 November 2006 - Revised: 11 September 2007 - Accepted: 18 September 2007 - Published: 2 October 2007

\begin{abstract}
Estimation of precipitable water (PW) in the atmosphere from ground-based Global Positioning System (GPS) essentially involves modeling the zenith hydrostatic delay (ZHD) in terms of surface Pressure $\left(P_{S}\right)$ and subtracting it from the corresponding values of zenith tropospheric delay (ZTD) to estimate the zenith wet (non-hydrostatic) delay (ZWD). This further involves establishing an appropriate model connecting PW and ZWD, which in its simplest case assumed to be similar to that of ZHD. But when the temperature variations are large, for the accurate estimate of PW the variation of the proportionality constant connecting PW and ZWD is to be accounted. For this a water vapor weighted mean temperature $\left(T_{m}\right)$ has been defined by many investigations, which has to be modeled on a regional basis. For estimating PW over the Indian region from GPS data, a region specific model for $T_{m}$ in terms of surface temperature $\left(T_{s}\right)$ is developed using the radiosonde measurements from eight India Meteorological Department (IMD) stations spread over the sub-continent within a latitude range of $8.5^{\circ}-$ $32.6^{\circ} \mathrm{N}$. Following a similar procedure $T_{m}$-based models are also evolved for each of these stations and the features of these site-specific models are compared with those of the region-specific model. Applicability of the region-specific and site-specific $T_{m}$-based models in retrieving PW from GPS data recorded at the IGS sites Bangalore and Hyderabad, is tested by comparing the retrieved values of PW with those estimated from the altitude profile of water vapor measured using radiosonde. The values of ZWD estimated at 00:00 UTC and 12:00 UTC are used to test the validity of the models by estimating the PW using the models and comparing it with those obtained from radiosonde data. The region specific $T_{m}$-based model is found to be in par with if not better than a similar site-specific $T_{m}$-based model for the near equatorial station, Bangalore. A simple site-specific
\end{abstract}

Correspondence to: C. Suresh Raju

(c_sureshraju@vssc.gov.in) linear relation without accounting for the temperature effect through $T_{m}$ is also found to be quite adequate for Bangalore. But for Hyderabad, a station located at slightly higher latitude, the deviation for the linear model is found to be larger than that of the $T_{m}$-based model. This indicates that even though a simple linear regression model is quite adequate for the near equatorial stations, where the temperature variations are relatively small, for estimating PW from GPS data at higher latitudes this model is inferior to the $T_{m}$-based model.

Keywords. Meteorology and atmospheric dynamics (Tropical meteorology) - Radio science (Atmospheric propagation; Remote sensing)

\section{Introduction}

Water vapor plays a major role in many of the atmospheric and geophysical phenomena, which include transfer of energy and formation of clouds and weather system. Weather forecast models demand water vapor information with high temporal resolution over a wide geographical region. Large variability of atmospheric water vapor content in short spatial and/or temporal scales makes its measurement rather involved and expensive. While direct measurement of water vapor content using Water Vapor Microwave Radiometer (WVMR) is very expensive, measurements using Radiosonde is time consuming. Satellite based microwave remote sensing, at the present state of its art, proves to be an effective tool for this purpose because it can provide the information even over inaccessible regions like oceans, etc. However, revisit time of polar orbiting satellites limits the temporal resolution. Satellite based water vapor measurements over land is far more difficult because of the large heterogeneity of land surface features. The land surface also acts as a warm background for microwave remote sensing of

Published by Copernicus Publications on behalf of the European Geosciences Union. 
atmosphere. As a result, most of the satellite-based measurements of atmospheric water vapor prove to be more useful over the oceanic regions.

A local network of GPS receivers is an effective alternative for water vapor remote sensing over the land (Businger et al., 1996) and this recently developed technique proves to be very effective in measuring Precipitable Water (PW), which is the height of the liquid water column when the entire water vapor in a vertical column of the atmosphere is condensed, as clouds and precipitation do not significantly affect the propagating GPS signals at 19 and $24 \mathrm{~cm}$ wavelengths. Rocken et al. (1993, 1995, 1997), demonstrated the capability of ground based GPS system for measuring PW with an accuracy of few millimeters. Emardson et al. (1998) and Tregoning et al. (1998) also have reported similar measurements of PW from GPS observations. However, most of these studies are carried out over the mid-latitude regions where the average $\mathrm{PW}$ is $<20 \mathrm{~mm}$. This points the importance of PW measurements using GPS over tropical region, where the atmospheric water vapor content is relatively large and perpetual cloud cover and precipitation severely affect other remote sensing techniques. The quantity of water vapor and its distribution in the atmosphere is greatly influenced by the geographical locations and climatic conditions. The Indian subcontinent experiences both tropical and extra-tropical climates. While the tropical atmosphere is relatively warm and can hold abundant quantity of water vapor, in the extra-tropical regions the atmospheric temperature as well as the water vapor content show large seasonal variation.

As the wet component of the zenith tropospheric delay (ZWD) derived from the GPS data by subtracting the hydrostatic component of the zenith delay (ZHD) from the zenith tropospheric delay (ZTD) depends primarily on the atmospheric water vapor content, this parameter could be used for estimating the PW in the atmosphere. Since the quantity of water vapor in the atmosphere is temperature dependent and both these parameters vary with altitude, accounting the effect of temperature profile in the estimation of PW is rather complicated. This problem is attempted by many investigators to arrive at a parameter called the weighted mean temperature $\left(T_{m}\right)$, which is the water vapor weighted vertically averaged temperature (Davis et al., 1985). While some of these models are simple linear types, some others take care of the periodic variations in $T_{m}$ also. Jade et al. (2005) made a consolidation of different models used for estimating $T_{m}$ and presented a comparison. Most of these are linear models (Mendes et al., 2000; Bevis et al., 1992, 1994; Solbrig, 2000; Schueler, 2001) based on surface temperature $\left(T_{S}\right)$, developed using the altitude profiles of atmospheric water vapor and temperature obtained from different parts of the globe. These linear models, considered as the global models, had a variability of about $\pm 20 \%$ (Bevis et al., 1994), which could be significant for many applications. Schueler (2001) also proposed a pair of harmonic models for $T_{m}$, accounting for its seasonal variation through a periodic function. Ross and
Rosenfeld (1997) after an extensive study on $T_{m}$ based on the meteorological data from 53 global stations (covering a wide latitudinal region) concluded that site-specific model would be superior to the geographically and globally invariant regression relationship used for $T_{m}$. But in tropics where the correlation between $T_{m}$ and $T_{s}$ decreases significantly this superiority is not very prominent. This could be due to the fact that the range of $T_{s}$ variations over the tropics would be rather small. In such cases it would be better to generate a region specific model. This prompted examining the potential of a Bevis-type regional model for the Indian meteorological conditions. A statistical relationship for $T_{m}$ in terms of $T_{s}$ was established considering eight stations spread over the continent from where good atmospheric data is available through the regular radiosonde measurements conducted by the India Meteorological Department (IMD). Of these eight locations (listed in Table 1) we have only one IGS (International GPS Service) station at the Indian Institute of Sciences (IISc) campus, Bangalore, the data from which could be used to retrieve the PW and validate the model. However, we have also examined the possibility of developing $T_{m}$-based site-specific regression models for these stations and examined its applicability at Bangalore (as the other locations do not have a ground based GPS receiver suitable for PW retrieval). Over and above these $T_{m}$-based models, the possibility of arriving a simple site-specific model for PW directly in terms of the non-hydrostatic component of zenith tropospheric delay analogous to that of ZHD in terms of surface pressure $\left(P_{S}\right)$ (Saastamoinen, 1972; Saha et al., 2007), and use it for the estimation of PW from GPS data of Bangalore, is also examined. The accuracies of these models are examined by comparing the retrieved PW with that obtained by integrating the water vapor density profile estimated from radiosonde measured altitude profiles of temperature and dew point temperature. The GAMIT-10.2 software is used for processing the GPS data (MIT and SIO, 2000) from Bangalore by incorporating the necessary supplementary data from eight other IGS stations (Fig. 1) downloaded from the IGS website, http://garner.ucsd.edu/pub/ and http://www.ngs.noaa.gov/CORS/Data.html.

\section{Methodology}

The range error $(\Delta R)$ caused by the propagation delay of microwave signal in the neutral atmosphere having refractivity $N$, which for convenience is defined as $N=10^{6} \times(n-1)$, where $n$ is the radio refractive index of the atmosphere in microwave frequencies, can be written as (Smith and Weintraub, 1953)

$\Delta R=10^{-6} \times \int N \cdot d s+[S-D]$

where $D$ is the direct distance of the receiver antenna from the satellite and $S$ is the curved path length actually traversed 
Table 1. Mean value of $T_{m}$ and $\Pi$ along with their range of variability at different Indian stations.

\begin{tabular}{lcccccc}
\hline Station & $\begin{array}{c}\text { Latitude } \\
\left({ }^{\circ} \mathrm{N}\right)\end{array}$ & $\begin{array}{c}\text { Longitude } \\
\left({ }^{\circ} \mathrm{E}\right)\end{array}$ & $\begin{array}{c}\text { Mean } \\
T_{m}(\mathrm{~K})\end{array}$ & $\begin{array}{c}\text { Range } \\
T_{m}(\mathrm{~K})\end{array}$ & $\begin{array}{c}\text { Mean } \\
\prod\end{array}$ & $\begin{array}{c}\text { Range } \\
\prod\end{array}$ \\
\hline Trivandrum & 8.5 & 76.9 & 287.8 & 4.1 & 0.164 & 0.002 \\
PortBlair & 11.6 & 92.5 & 287.6 & 3.6 & 0.164 & 0.002 \\
Bangalore & 12.9 & 77.7 & 284.1 & 6.0 & 0.162 & 0.003 \\
Kolkata & 22.6 & 88.5 & 287.3 & 12.0 & 0.164 & 0.007 \\
Ahmedabad & 23.1 & 72.6 & 287.3 & 12.4 & 0.164 & 0.007 \\
Guwahati & 26.1 & 91.6 & 285.3 & 11.8 & 0.163 & 0.007 \\
Delhi & 28.6 & 77.1 & 284.6 & 17.3 & 0.162 & 0.010 \\
Srinagar & 34.1 & 74.8 & 274.3 & 24.6 & 0.156 & 0.014 \\
\hline
\end{tabular}

by the wave to reach the receiver antenna. Often ray tracing technique is used to estimate $\Delta R$ which accounts for the varying refractive index with altitude and the spherical shape of earth's atmosphere while calculating the contributions of range error from the excess distance due to bending of wave path (second part in Eq. 1) in off-nadir angles. To implement the ray tracing the atmosphere is assumed to be divided into a series of concentric homogeneous spherical layers each of which is characterized by a mean refractive index. Successive application of Snell's law to each of these spherically stratified atmospheric layers allow the numerical integration of refractive effect. In zenith direction as the refractive bending is absent, the delay is purely due to retardation in which case the $\Delta R$ is referred to as "zenith tropospheric delay" or ZTD. In this case Eq. (1) reduces to a simple integral of $N$ along the zenith direction

$\mathrm{ZTD}=10^{-6} \times \int_{Z_{\mathrm{ant}}}^{\mathrm{TOA}} N \cdot d s$

The integration is carried out from antenna height $\left(Z_{\text {ant }}\right)$ to the top of the neutral atmosphere (TOA). The refractivity, $N$, has two components; the hydrostatic or dry component $\left(N_{D}\right)$, which depends on Pressure $(P)$ and Temperature $(T)$ as $N_{D}=k_{1} \times P / T$, and the non-hydrostatic or wet component $\left(N_{W}\right)$, which depends on Water vapor partial pressure (e) and $T$ as $N_{W}=k_{2} \times e / T+k_{3} \times e / T^{2}$. The values of the constants $k_{1}, k_{2}$ and $k_{3}$ are given as $k_{1}=77.60 \pm 0.05 \mathrm{~K} \mathrm{mb}^{-1}$, $k_{2}=70.4 \pm 2.2 \mathrm{~K} \mathrm{mb}^{-1}, \quad k_{3}=(3.739 \pm 0.0012) \times 10^{5} \mathrm{~K}^{2} \mathrm{mb}^{-1}$ (Bevis et al., 1994). This permits (Bevis et al., 1994; Askne and Nordius, 1987; Neill, 1996) the estimation of Zenith Hydrostatic Delay (ZHD) and Zenith Wet Delay (ZWD), separately as

$\mathrm{ZHD}=10^{-6} \cdot \int N_{D} d z=10^{-6}\left\{k_{1} \int \frac{P}{T} d z\right\}$

$\mathrm{ZWD}=10^{-6} \cdot \int N_{W} d z=10^{-6}\left\{k_{2} \int \frac{e}{T} d z+k_{3} \int \frac{e}{T^{2}} d z\right\}$

In the above equations $P, e$ and $T$ are respectively the altitude profiles of the hydrostatic pressure expressed in $\mathrm{mb}$,

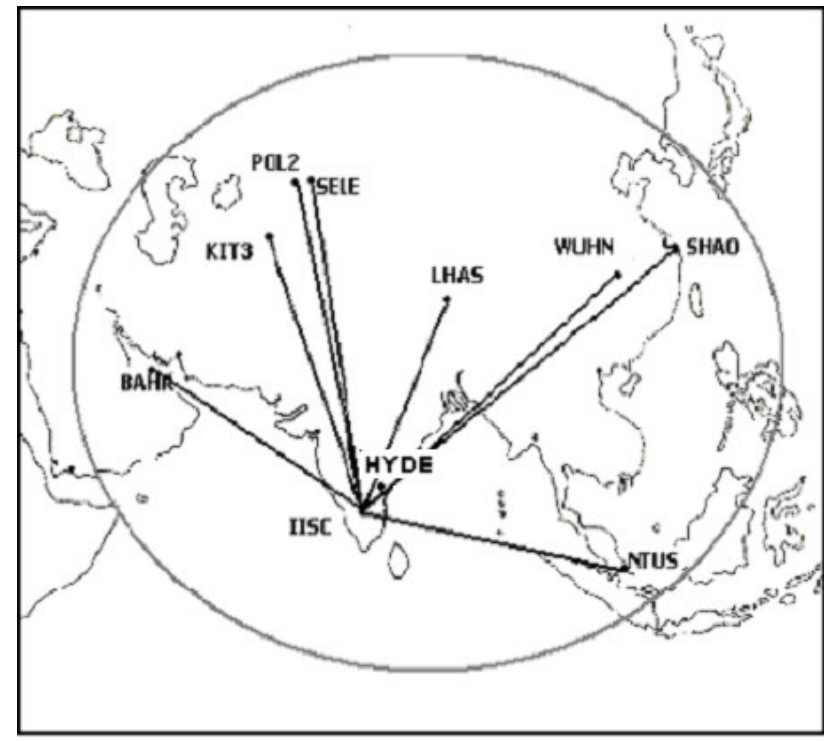

Fig. 1. The network of IGS stations around Bangalore (IISC) and Hyderabad (HYDE) used in the present study. The other stations are Manama (BAHR), Kitab (KIT3), Bishkek (POL2), Almaty (SELE), Lhasa (LHAS), Wuhan city (WUHN), Sheshan (SHAO) and Singapore (NTUS).

partial pressure of atmospheric water vapor in $\mathrm{mb}$ and atmospheric temperature in Kelvin. For establishing the empirical relation connecting ZHD and ZWD with easily available surface meteorological parameters (which is essential for the estimation of PW from GPS data) the dependence of ZHD and surface pressure $\left(P_{S}\right)$ and the dependence of ZWD on columnar water vapor are examined.

For the retrieval of PW from GPS data the daily phase observations in the Receiver-Independent Exchange (RINEX) format are collected at Bangalore (IISc) along with eight other IGS stations. The eight IGS stations are chosen based on a thorough optimization study (Tregoning et al., 1998) starting with about 22 available IGS stations in and around Bangalore (Suresh Raju et al., 2005). The optimum 

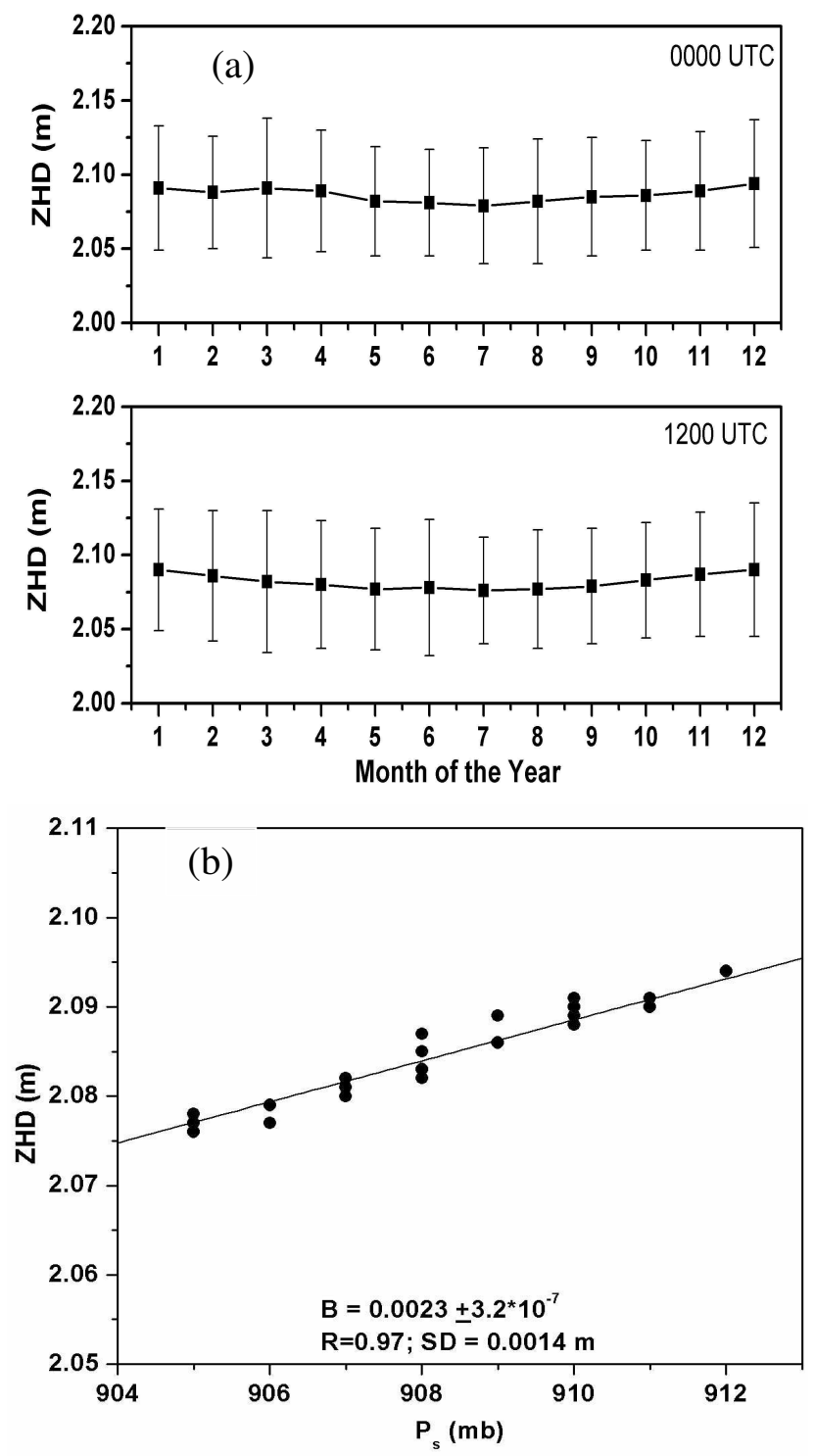

Fig. 2. Monthly mean values of dry range error in the zenith direction (ZHD) for Bangalore at 00:00 UTC and 12:00 UTC, respectively in the upper panel and lower panel estimated by using mean profiles of atmospheric pressure $(P)$ and temperature $(T)$ for the period 1995-1997, obtained from the radiosonde data (vertical bars in both the panels are standard deviations in each month due to the day-to-day variations of $P$ and $T$, estimated by applying the error propagation formula $(\mathrm{Ku}, 1966))(\mathbf{a})$, and dependence of ZHD on surface pressure $\left(P_{S}\right)$ is derived using the monthly mean values of ZHD and $P_{S}(\mathbf{b})$.

combination is selected (Fig. 1) based on the normalized r.m.s. value of the double differencing to be $<0.25$ cycles and the post fit r.m.s. value to and by the satellite is $<5$, during the GAMIT processing keeping the mandatory requirement of using GPS data from the same satellite for these stations. The two hourly bins required for processing the data is chosen such that one such bin will match with the morning radiosonde sounding (00:00 UTC) and another with the evening radiosonde sounding (12:00 UTC) of the IMD at Bangalore. The GAMIT estimates the propagation delay (Davis et al., 1985; MIT and SIO, 2000) mapped to zenith direction $\left(\mathrm{ZTD}_{\mathrm{GPS}}\right)$ using the mapping function developed by Niell (1996). To minimize the error due to multi-path and effect of lower troposphere where spatial gradients in atmospheric refractive index can be significant, a lower cutoff value of about $15^{\circ}$ is fixed for the minimum elevation angle (Ohtani et al., 2000). The hydrostatic component of zenith range error (ZHD) is estimated through models developed based on the atmospheric pressure at surface. This component is subtracted from the GPS derived $Z_{T D} D_{\text {GPS }}$, to estimate ZWD and hence to derive PW.

It would be worth in this context to note that the IGS station and the IMD station (from where radiosondes are being launched regularly) at Bangalore are not collocated. While they are separated horizontally by $\sim 6 \mathrm{~km}$, the IMD site is situated at an elevated location which is $\sim 100 \mathrm{~m}$ above that of the IGS site. The surface met parameters are also measured at the IMD site. The surface pressure, which will be used along with the GPS-derived Zenith delay to estimate the PW is obtained from the $P_{S}$ measurements at the IMD site after correcting for the station elevation using a mean scale height of $8 \mathrm{~km}$, arrived from the measured pressure profiles. The effect of horizontal separation however, is neglected.

\section{Linear model of ZHD for Bangalore from radiosonde data}

Estimation of ZWD from ZTD $_{\mathrm{GPS}}$ essentially requires empirical model for ZHD in terms of surface meteorological parameters. For this, mean profiles of $P, T$ and $e$ in different months are generated using the daily radiosonde data collected at 00:00 and 12:00 UTC by the IMD at Bangalore for the period 1995 to 1997 . These mean profiles in different months usually extend up to $\sim 26 \mathrm{~km}(\sim 7 \mathrm{mb}$ level) for $P$ and $T$ and up to $\sim 12 \mathrm{~km}$ for $e$. Using these profiles the mean value of ZHD (the true zenith hydrostatic delay) in different months for Bangalore are estimated employing Eq. (3). The month-to-month variation of mean ZHD thus estimated is presented in Fig. 2a separately for 00:00 and 12:00 UTC. The vertical bars indicate the standard deviations depicting the extent of day-to-day variability in ZHD for each month, which amounts to be around $\pm 5 \mathrm{~cm}$. The annual mean value of ZHD is $\sim 2.1 \mathrm{~m}$ and the deviation of mean ZHD in a month from this annual mean is $<1.5 \mathrm{~cm}$. A close examination of this annual variation of ZHD reveals that the pattern is very similar to that of surface pressure $\left(P_{S}\right)$ at Bangalore. This prompted establishing a linear relation between ZHD and $P_{S}$. A scatter plot of mean $P_{S}$ with mean ZHD in different months generated for this is presented in Fig. 2b. Values corresponding to both 00:00 and 12:00 UTC are incorporated in this scatter plot (resulting 24 points in total). Obviously 
this figure shows a linear increase in ZHD with increase in $P_{S}$ with very little scatter. Taking note of this fact, a simple linear relationship connecting $P_{S}$ with ZHD is established (Saha et al., 2007) in the form

$\mathrm{ZHD}=q_{d} \times P_{s}$

Through regression analysis the value of the proportionality coefficient, $q_{d}$, turns out to be $2.3 \pm 0.00032 \mathrm{~mm} \mathrm{mb}^{-1}$ with a correlation coefficient of 0.97 , which is significant (Fisher, $1970)$ at $p<0.001$ level of significance, with a standard deviation for the fitted line $(\sigma)$ of $0.0014 \mathrm{~m}$.

The applicability of this empirical model for predicting the daily values of zenith hydrostatic delay is examined using the upper air data obtained through daily radiosonde ascents for the year 2001-2002. Those good radiosonde data for which the altitude profiles of $P$ and $T$ extend above $25 \mathrm{~km}$ and those of $e$ extending up to the upper troposphere only are considered for this purpose. However, even with this stringent condition sufficient profiles (around 1065) of $P, T$ and $e$ were available to generate a good statistics. The normalized mean of absolute difference between the true estimates (Eq. 3a) and model estimate (Eq. 4) of ZHD was less than $\pm 8 \mathrm{~mm}$ which comes out to $\sim 0.4 \%$ of the mean value. This would lead to an uncertainty of around $\pm 1.2 \mathrm{~mm}$ in the estimated PW.

\section{Linear model of PW in terms of ZWD for Bangalore from radiosonde data}

The monthly mean values of the wet component of zenith tropospheric delay (ZWD) are estimated using Eq. (3b) employing the mean altitude profiles of $e$ and $T$ obtained from daily radiosonde profiles of Bangalore for the period 19951997. The month-to-month variation of ZWD for 00:00 and 12:00 UTC are depicted in Fig. 3a. The mean ZWD varies from $15 \mathrm{~cm}$ to $28 \mathrm{~cm}$ with a day-to-day variability of $\pm 12 \mathrm{~cm}$ (nearly $45 \%$ of the mean value). This large variability in ZWD is mainly due to corresponding variations in atmospheric relative humidity. The altitude profile of water vapor density $\left(\rho_{V}\right.$, in $\left.\mathrm{kg} \mathrm{m}^{-3}\right)$ is estimated from the altitude profiles of $e$ and $T$ employing the equation of state $\left(e=\rho_{v} \quad R_{v} \quad T\right)$ for water vapor. Integrating the altitude profile of $\rho_{v}$ up to its highest altitude the columnar (integrated) water vapor (IWV) and Precipitable water vapor (PW) are estimated as

$\mathrm{IWV}=\int_{Z_{\mathrm{ant}}}^{\mathrm{TOA}} \rho_{v} d z\left(\mathrm{~kg} \mathrm{~m}^{-2}\right)$

$\mathrm{PW}=\frac{\mathrm{IWV}}{\rho_{l}}(\mathrm{~m})$

where $\rho_{l}\left(\mathrm{~kg} \mathrm{~m}^{-3}\right)$, is the density of liquid water, which is approximated as $10^{3} \mathrm{~kg} \mathrm{~m}^{-3}$ for the present study. Often PW is expressed in mm to avoid small decimal values. In order to establish an empirical relation connecting PW with ZWD, the mean value of ZWD (from Eq. 3b) is plotted against the
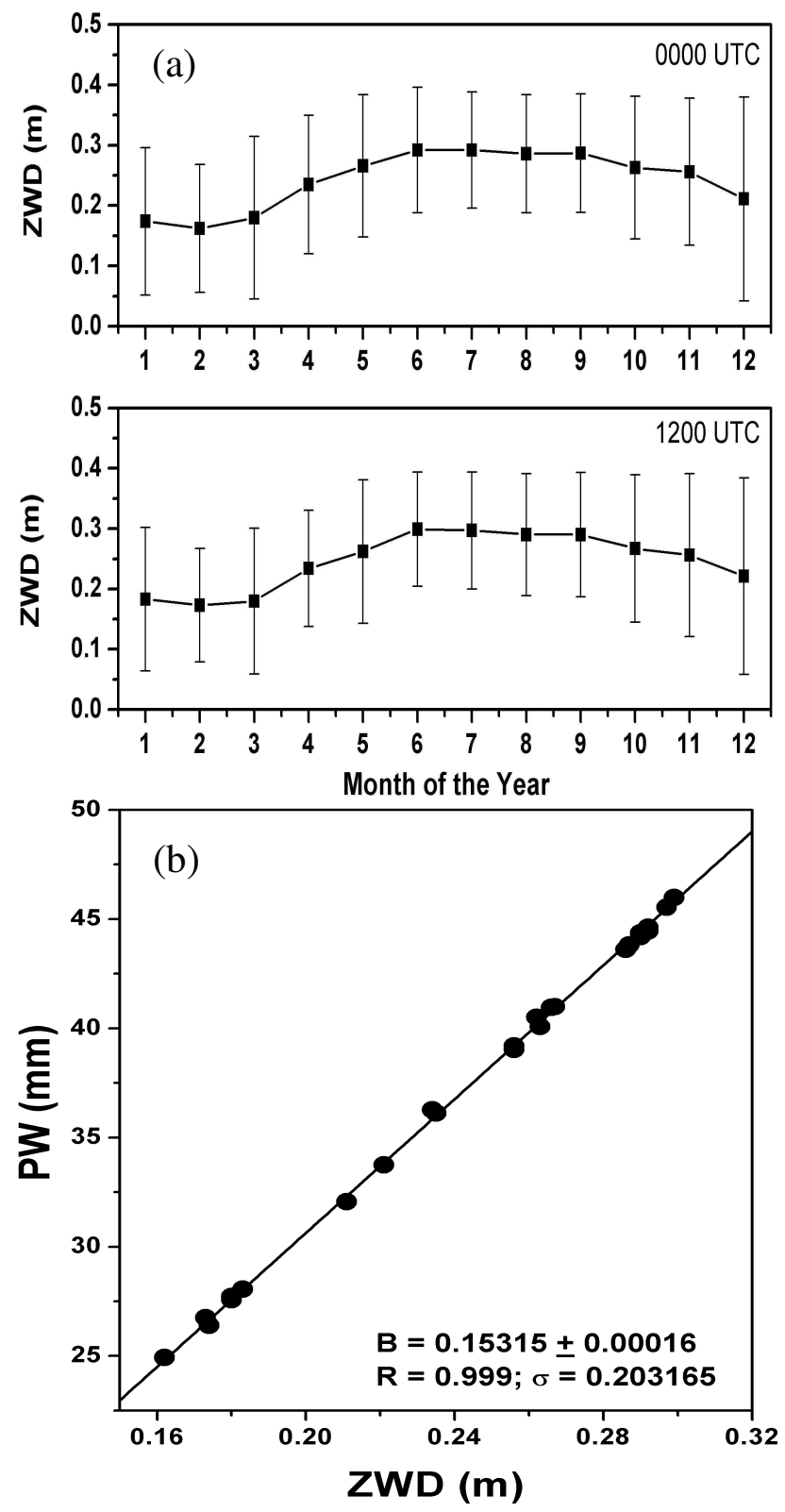

Fig. 3. Monthly mean values of wet range error in the zenith direction (ZWD) for Bangalore at 00:00 UTC and 12:00 UTC, respectively in the upper panel and lower panel estimated by using the mean profiles of partial water vapor pressure $(e)$ and temperature ( $T$ ) for the period 1995-1997, obtained from radiosonde data (vertical bars in both the panels are standard deviations in each month due to the day-to-day variations of $e$ and $T$, estimated by applying the error propagation formula $(\mathrm{Ku}, 1966))(\mathbf{a})$, and dependence of Integrated columnar (precipitable) water vapor (PW) on ZWD is derived using monthly mean values of ZWD and PW (b).

corresponding value of PW; both estimated using the mean altitude profile of water vapor. A scatter plot thus obtained is presented in Fig. 3b. As can be seen from this figure the points are mostly aligned along the straight line. The 


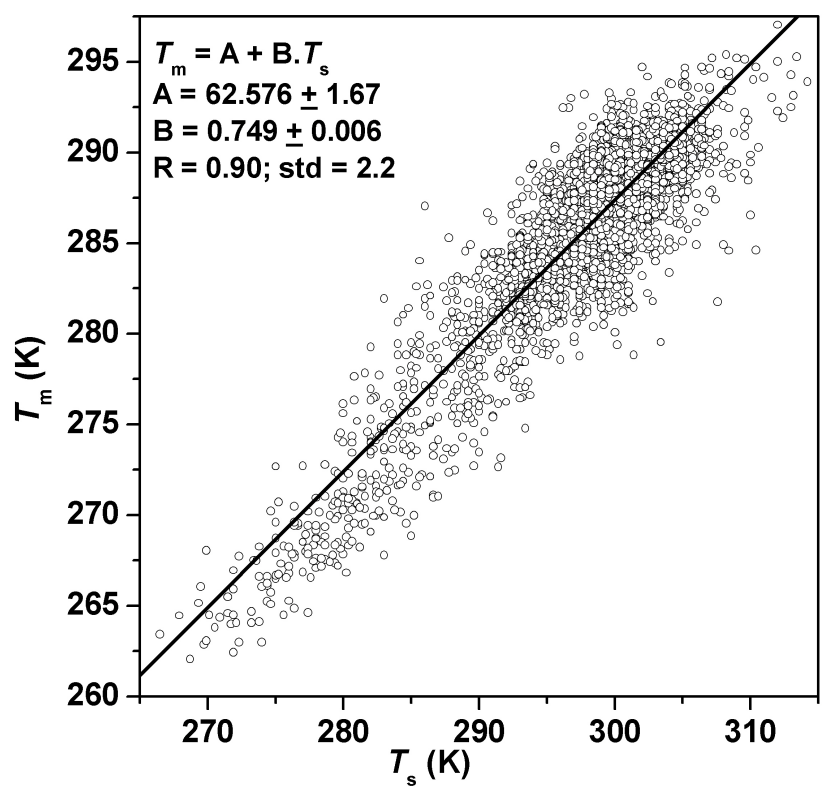

Fig. 4. Variation of $T_{m}$ with $T_{s}$ based on upper air data for the period 1995-1997 for eight selected met-stations spread over Indian subcontinent $\left(8.5^{\circ} \mathrm{N}-32.6^{\circ} \mathrm{N}\right)$.

empirical relation connecting the two obtained through regression analysis, yielding a correlation coefficient of 0.999 , is of the form,

$\mathrm{PW}=(0.153 \pm 0.00016) \times \mathrm{ZWD}$

The accuracy of the model is further examined by studying the absolute difference of model prediction from the true estimate employing daily radiosonde measurements for the period 2001-2002. The mean absolute difference in PW was found to be $\sim 1.6 \mathrm{~mm}$. Equation (6) is used in later part of this manuscript for estimating precipitable water vapor from GPS derived zenith wet delay $\left(\mathrm{ZWD}_{\mathrm{GPS}}\right)$.

\section{Adaptation of Bevis model for Indian region}

As seen from Eq. (3b), the wet component of zenith delay depends on the altitude profiles of $e$ and $T$. But the amount of water vapor present in air itself is related to temperature, which complicates the modeling. This prompted many investigators to account for the altitude variation of temperature through a term called weighted mean temperature $\left(T_{m}\right)$ and use it along with PW to relate the later with ZWD. Askne and Nordius (1987) attempted to relate the PW and ZWD through a linear relation given as:

$\mathrm{PW}=\Pi \times \mathrm{ZWD}$

Where, $\Pi$ is the proportionality coefficient, which is related to $T_{m}$ (Askne and Nordius, 1987; Bevis et al., 1992). Note that this relationship is similar to that presented through
Eq. (6) except for the fact that in Eq. (7) the variation of the proportionality coefficient $(\Pi)$ with temperature is taken into account through the weighted mean temperature $T_{m}$ defined as (Bevis et al., 1994) $T_{m}=\frac{\int(e(z) / T(z)) d z}{\int\left(e(z) / T^{2}(z)\right) d z}$, where $e$ is the water vapor partial pressure expressed in $\mathrm{mb}$ and temperatures $T$ and $T_{m}$ in K. $\Pi$ is non-linearly related to $T_{m}$, though the typical value of $\Pi$ is $\sim 0.15$, it varies from place to place and also depends on seasons. Being a function of $T_{m}, \Pi$ varies as much as $20 \%$ with latitude, altitude and time of the year (Bevis et al., 1994). Using the altitude profiles of $e$ and $T$ from various mid-latitude stations $\left(27^{\circ}\right.$ to $\left.65^{\circ} \mathrm{N}\right)$ Bevis et al. (1992) arrived an empirical relation connecting $T_{m}$ and $T_{S}$ of the form $T_{m}=70.2+0.72 \times T_{s}$. This relation, hereafter will be referred to as "Bevis model", for convenience. A similar empirical model for $T_{m}$ based on radiosonde measurements from eight locations (Table 1) over the Indian subcontinent employing about 4104 good radiosonde profiles with humidity measurements extending up to or above $10 \mathrm{~km}$ during the period 1995 to 1997 is attempted. The value of $T_{m}$ estimated for different surface temperatures are presented in a scatter plot shown in Fig. 4. A linear relationship, established between the two following regression analysis and the best-fit straight line, is also shown in this figure. This yields an empirical relation between $T_{m}$ and $T_{s}$ in the following form

$T_{m}=(62.6 \pm 1.67)+(0.75 \pm 0.006) \times T_{s}$

This figure shows that the values of $T_{m}$ vary in the range 265 to $295 \mathrm{~K}$ for a corresponding variation of 265 to $315 \mathrm{~K}$ in $T_{s}$. There is a high density of points for $T_{s}>290 \mathrm{~K}$ and low density of points for $T_{s}<273 \mathrm{~K}$ (mostly belong to Srinagar $\left(32.67^{\circ} \mathrm{N}\right)$ located at $1600 \mathrm{~m}$ above m.s.1.). In Bevis et al. (1992), there were quite a few cases with estimated $T_{m}$ values being larger than $T_{s}$, which was attributed to strong temperature inversions near the surface, a phenomenon usually encountered at high-latitudes. However, such cases seldom encountered in our analysis. It would be worth in this context to note that similar attempts to relate $T_{m}$ with $T_{s}$ was pursued by various investigators at different contexts, a consolidation of which is provided by Jade et al. (2005). They arrived at different values for the coefficients in Eq. (8). While the intercept varied in the range $50.4 \mathrm{~K}$ to $86.9 \mathrm{~K}$, the slope varies in the range 0.65 to 0.79 . In this scenario it would be more meaningful to compare the end product, $T_{m}$, for the range of $T_{S}$ values usually encountered than examining the agreement in coefficients of "Bevis" and "Bevis Adapted for Indian region (BAI) regional model" (Eq. 8). For the range of $T_{s} 282$ to $312 \mathrm{~K}$, which is usually encountered over the study region (Fig. 4) the values of $T_{m}$ obtained from Bevis model ranges from 273 to $295 \mathrm{~K}$, while that from Eq. (8) ranges from 274 to $297 \mathrm{~K}$, resulting a net difference of $1-2 \mathrm{~K}$, which is not very significant. However, for a more quantitative comparison, the PW was estimated for different days (about 605 days) during 2001-2002 employing both these equations and the r.m.s. deviation between the two was found 

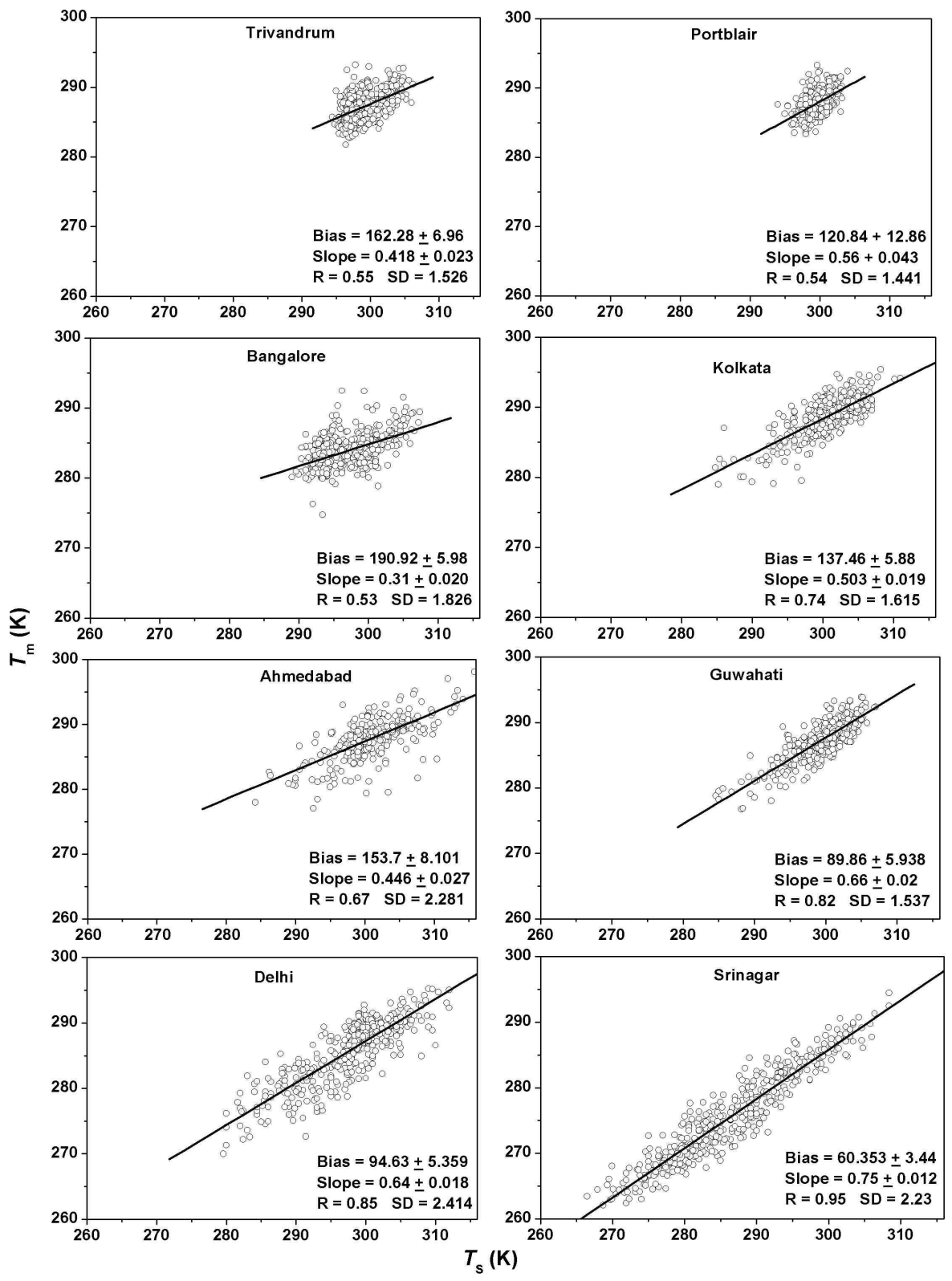

Fig. 5. Variation of $T_{m}$ with $T_{s}$ for the individual stations located at $8.5^{\circ} \mathrm{N}-32.6^{\circ} \mathrm{N}$ over Indian sub-continent based on upper air data for the period 1995-1997. the geographical locations of these stations are furnished in Table 1 . The dynamical range of $T_{m}$ and $T_{S}$ and the correlation of $T_{m}$ with $T_{S}$ increase with increase in latitude.

to be $<0.18 \mathrm{~mm}$, which is rather small considering the regional differences (Jade et al., 2005) which is $\sim 20 \%$.

Based on the Eq. (8) the mean values of $\Pi$ and $T_{m}$ as well as their month-to-month variability are examined for different Indian stations, which are summarized in Table 1. The features are quite obvious. The range of variability is small for the low latitude stations, and increases with increasing latitude. For Bangalore the mean value of $\Pi$ is about 0.0162 , which is marginally larger than the typical value reported for American stations (Bevis et al., 1994; Ross and Rosenfeld, 1997) based on Bevis model.
In the above we have considered eight stations spread over the Indian subcontinent extending from tropical to midlatitudes for establishing the relationship between $T_{m}$ and $T_{s}$. But as noted earlier, Ross and Rosenfeld (1997) recommended for a site-specific model as superior to geographically invariant regression. This aspect also is examined in the Indian scenario. Figure 5 shows a scatter plot of $T_{m}$ with $T_{s}$ separately for the eight stations considered for the analysis along with the best-fit regression line in each case. The regression coefficients thus arrived is also shown in the respective frames. This model hereafter will be referred to as "BAI 


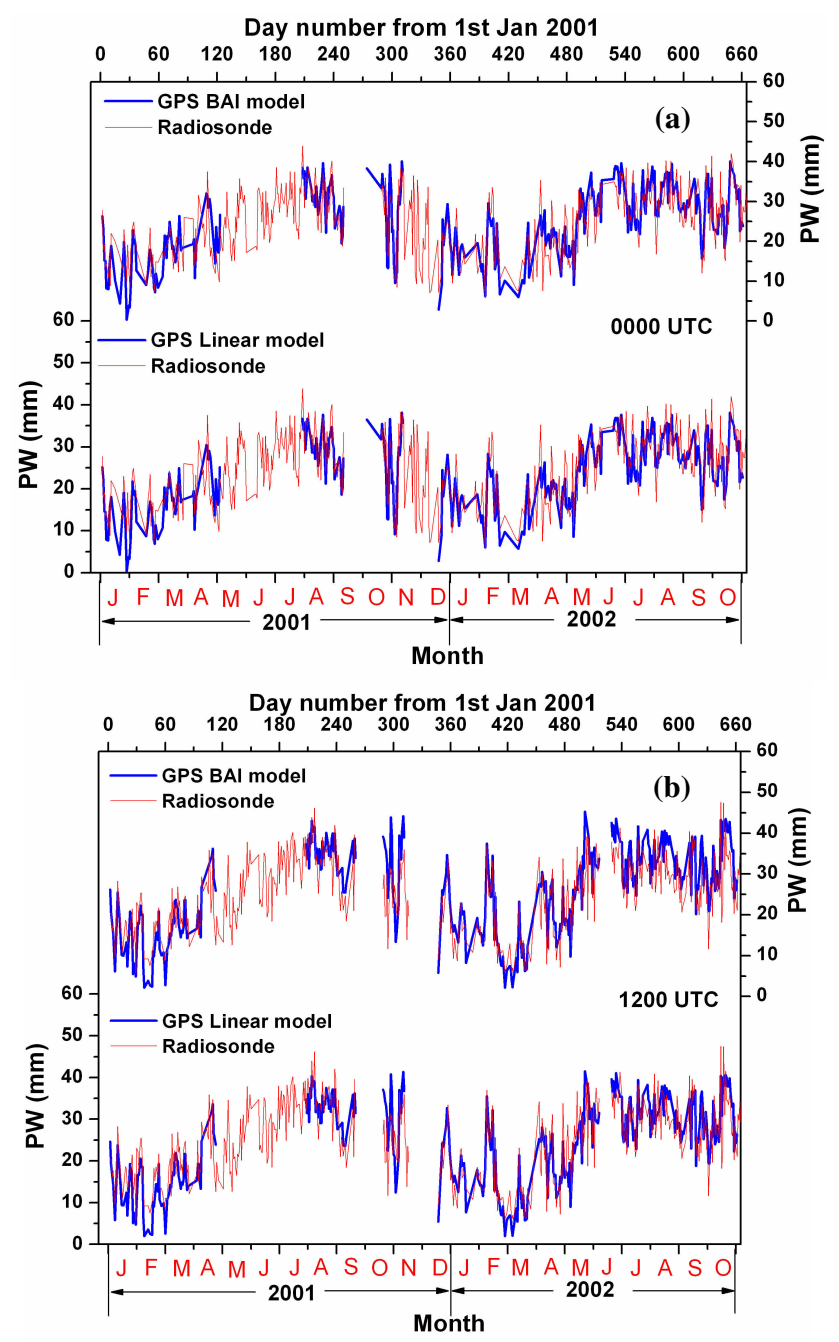

Fig. 6. Daily precipitable water estimated from GPS data for Bangalore using BAI regional model and site-specific linear model along with those derived from radiosonde data at 00:00 UTC (a) and 12:00 UTC (b) for the period January 2001 to October 2002.

site-specific model". As can be seen from this figure, for the tropical stations the points are mostly clustered around a small region because the range of $T_{s}$ variations is small. The spread of the points increases with increase in latitude. For the tropical stations the derived coefficients deviate significantly from that of Eq. (8), while those for the midlatitude stations tend to become closer. On comparing the values of $T_{m}$ obtained from the "BAI regional" model and "BAI site-specific" model for the range of $T_{S}$ values encountered at Bangalore (287-307 K), it can be seen that while the former yields $T_{m}$ in the range 277.9 to $292.9 \mathrm{~K}$, the latter yields $T_{m}$ in the range 279.9 to $286.1 \mathrm{~K}$, resulting a deviation of around 2 to $6 \mathrm{~K}$ depending on $T_{s}$. Note that the difference between "Bevis" and "BAI regional" models in this case is only around $1 \mathrm{~K}$.

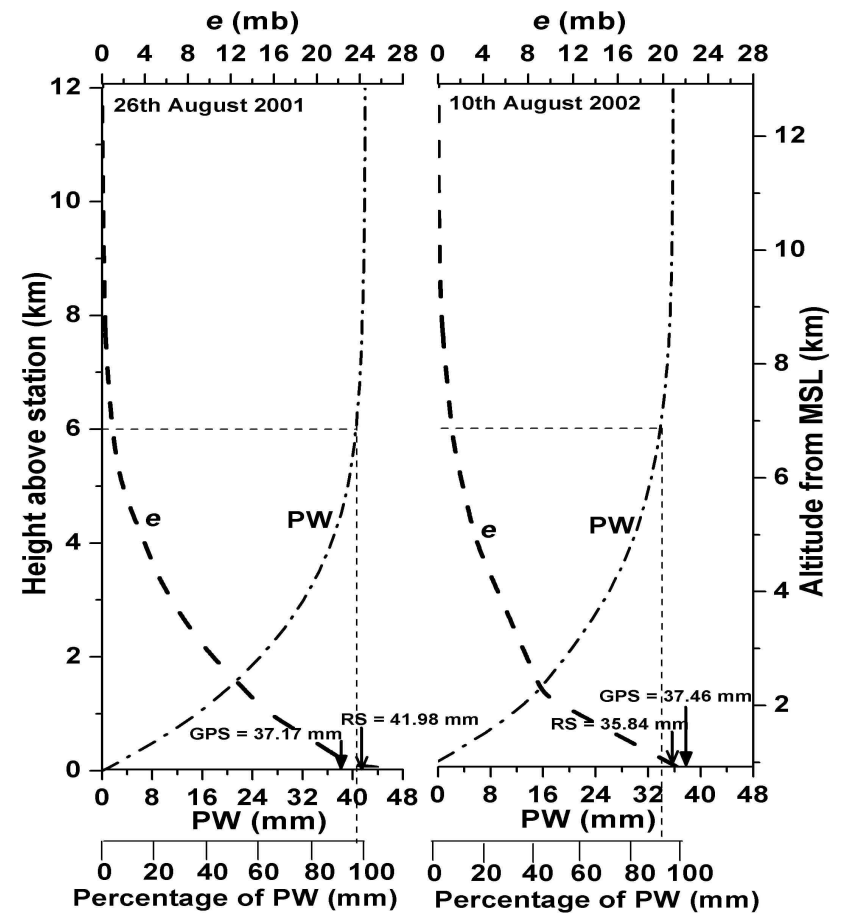

Fig. 7. Altitude profiles of water vapor partial pressure $(e)$ from radiosonde, PW up to different altitudes and its percentage to column integrated value on two typical days for Bangalore. The column integrated PW from $e$ profile and $\mathrm{PW}_{\mathrm{GPS}}$ are marked. Left side axis shows the height above the surface and right side axis shows the altitude above the m.s.l.

\section{Estimation of PW from GPS data}

The GAMIT uses the GPS data at $30 \mathrm{~s}$ interval from eight stations along with that of Bangalore (Fig. 1) for a period of two hours and outputs one mean value of $\mathrm{ZTD}_{\mathrm{GPS}}$. Using this algorithm $\mathrm{ZTD}_{\mathrm{GPS}}$ for Bangalore is estimated at 2$\mathrm{h}$ interval for different days during the period 2001-2002. The accuracy of GPS data processing is confirmed by comparing these values with those reported by the IGS on their sites at SOPAC/CSRC archive available at http://garner.ucsd. edu/pub/troposphere/ (the absolute difference is found to be $<8 \mathrm{~mm}$ ). Once confidence is established in our GPS data analysis, the hydrostatic component of zenith tropospheric delay is estimated, employing Eq. (4) using the appropriate value of $P_{S}$, and subtracted it from the $\mathrm{ZTD}_{\mathrm{GPS}}$ to obtain the $\mathrm{ZWD}_{\mathrm{GPS}}$ for different days during the study period. The $P_{S}$ values measured at the IMD site are corrected for the elevation difference as detailed earlier and used for this purpose. These values of $Z W_{\text {GPS }}$ at 00:00 UTC and 12:00 UTC are used for estimating PW, employing the site-specific linear model (Eq. 6) described in the first part of this paper as well as the regional model ("BAI regional") established based on $T_{m}$ (Eqs. 7, 8) and site-specific $T_{m}$-based model ("BAI sitespecific" refer Fig. 5) for Bangalore are used. The basic 

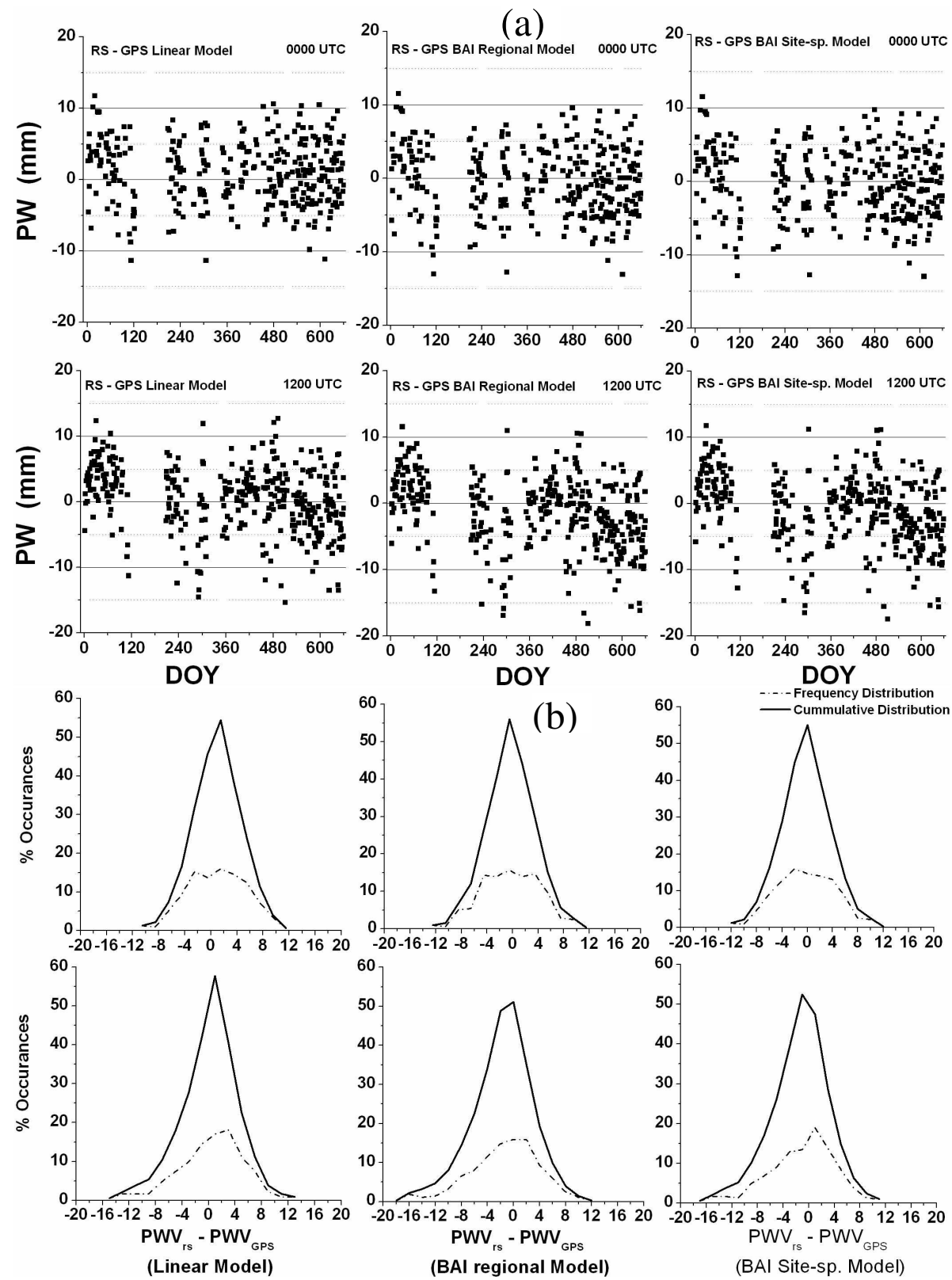

Fig. 8. Difference between Radiosonde derived PW and GPS derived PW for 00:00 UTC and 12:00 UTC for Bangalore. The left-hand side panels show the deviation of $\mathrm{PW}_{\mathrm{GPS}}$ estimated employing the linear model from radiosonde derived values, while the middle and right-hand side panels show the same for BAI regional model and BAI site-specific model (a). Percentage distribution and cumulative percentage (number of occurrences above a particular value in the case of positive deviations and number of occurrences below a particular value in the case of negative deviations) distribution of the deviations shown on different panels of Fig. 9a (b).

difference between the linear and BAI models is that while the latter models accounts for the effect of temperature variations the former does not.

In order to establish the general applicability of the model, PW is estimated from the GPS data ( PW $\left._{\mathrm{GPS}}\right)$ for 22 months during the period January 2001 to October 2002, a time series plot of which is presented in Fig. 6 (blue curve). The top panel in this figure shows the PW values retrieved for 00:00 UTC and the base panel those for 12:00 UTC. For a direct comparison, the value of PW derived from radiosonde profiles for the respective timings is also plotted along the same estimated from the GPS data. The agreement between the two (GPS and radiosonde) is fairly good. Though in most of the cases the profiles of water vapor density derived from 

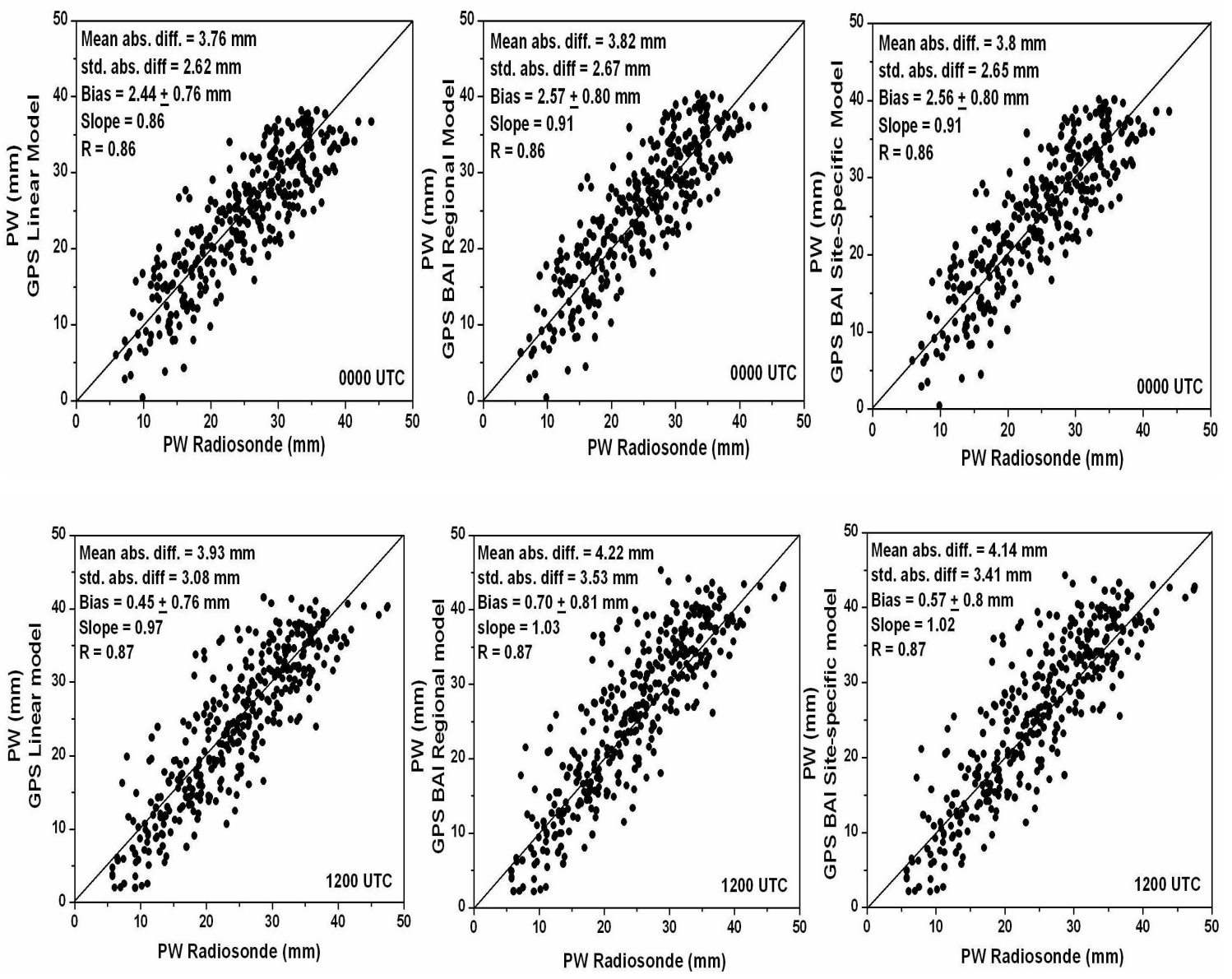

Fig. 9. A scatter plot of $\mathrm{PW}_{\mathrm{GPS}}$ estimated using linear model and BAI models verses the PW derived from the altitude profiles of water vapor estimated from radiosonde data for Bangalore. Scatter plot generated from the time-series data of PW $_{\mathrm{GPS}}$ and PW derived from radiosonde for the period January 2001 to October 2002.

radiosonde exceeds $6 \mathrm{~km}$, in a few cases they could be confined to a lower altitude, which could be one of the reasons for over estimate of $\mathrm{PW}_{\mathrm{GPS}}$. But even for those cases in which the water vapour profiles extend up to the upper troposphere, $\mathrm{PW}_{\mathrm{GPS}}$ could be an overestimate. Figure 7 shows a typical example of two cases in which the $e$ profile is extending up to $\sim 13 \mathrm{~km}$, in one case the GPS underestimates the PW while in the other it overestimates. Note that in all cases the PW is estimated from the station altitude up to the relevant top-altitude. It may also be noted that $>95 \%$ of the columnar water vapour (or PW) is contributed by the altitudes below $6 \mathrm{~km}$.

\section{Results and discussions}

Figure 6 shows that the values of PW is relatively low during the period December-February $(<25 \mathrm{~mm})$ with a day-to-day variation of $\sim 4 \mathrm{~mm}$. It shows a gradual increase during the March-April period and reaches its peak during June, when the southwest monsoon sets over the southern part of Indian peninsula. It remains fairly high, with mean value $>32 \mathrm{~mm}$, up to September and starts decreasing thereafter. It may also be noted that the atmospheric water vapor content is relatively large during the evening hours ( $\sim 12: 00$ UTC).

The GPS derived PW is compared with that estimated by integrating the humidity profile derived from radiosonde data on a day-to-day basis. The difference between the two on each day is presented in Fig. 8a. Only those radiosonde data for which the water vapor density profiles extending up to upper troposphere, are used for this purpose. The top panel shows a plot of this difference at 00:00 UTC and the base panel the same for 12:00 UTC. In most of the cases the deviation is less than $\pm 10 \mathrm{~mm}$. Deviations exceeding $\pm 10 \mathrm{~mm}$ are mostly observed during April-May and September-November period which could partly be due to large spatial heterogeneity in water vapor distribution associated with short range convective systems. It is also interesting to note that compared to 12:00 UTC, the number of cases in which the deviations exceed $\pm 10 \mathrm{~mm}$ is very small at 00:00 UTC. 
0000 UTC

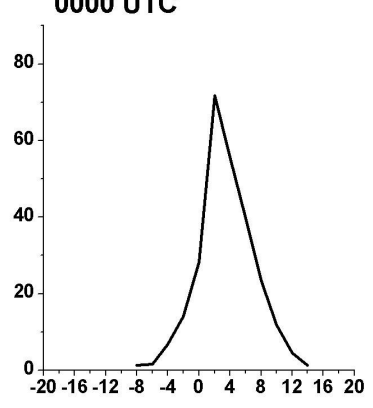

1200 UTC

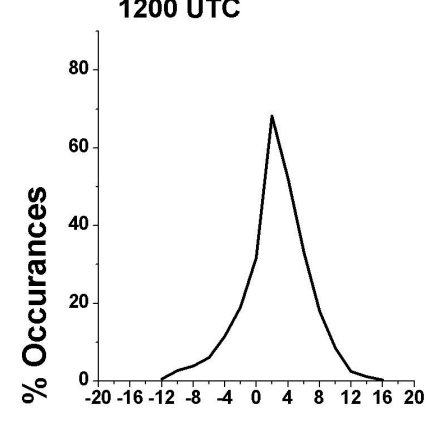

Composite

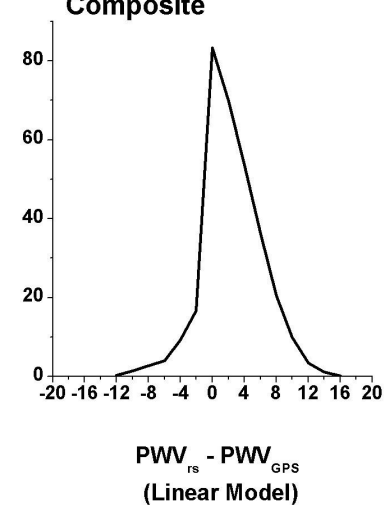

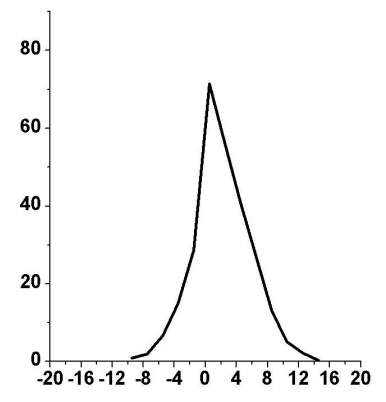

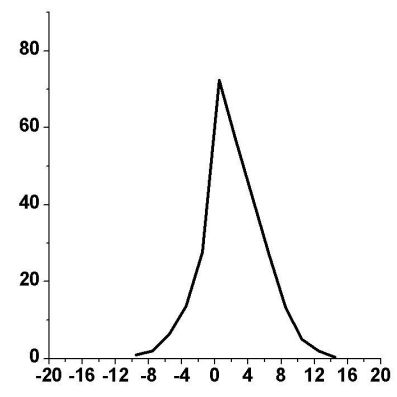

(b)
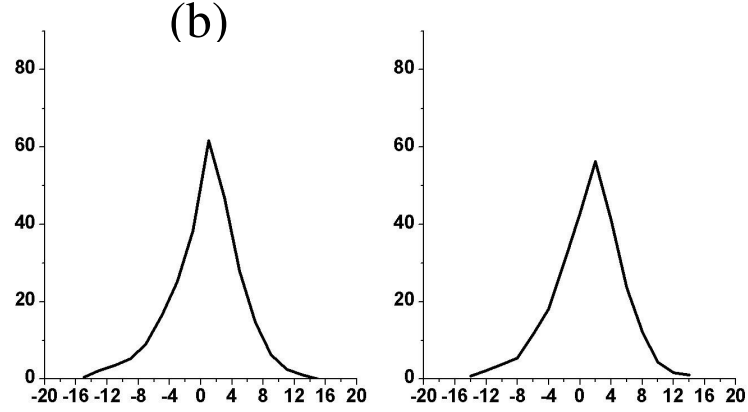

(c)
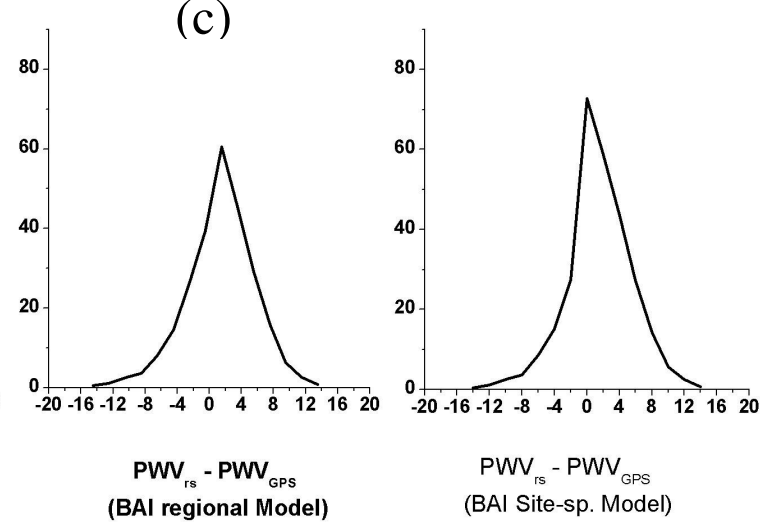

Fig. 10. Cumulative percentage (number of occurrences above a particular value in the case of positive deviations and number of occurrences below a particular value in the case of negative deviations) distribution of the deviations shown on different panels of Fig. 8a after accounting for the height correction in water vapor profile at 00:00 UTC (a), 12:00 UTC (b) and combining both 00:00 and 12:00 UTC (c).

Moreover, on examining the relative merits of the three models based on deviations it is seen that large deviations exceeding $\pm 10 \mathrm{~mm}$ is very small for the case of linear model compared to the other two. A plot of the frequency distribution of these deviations along with its cumulative percentage distribution (taking sign also into account) for the three cases is presented in Fig. 8b. The cumulative distribution is relatively sharp in the case of linear model indicating that the large deviations are less probable. While the probability of positive deviations are more for linear model, in around $30 \%$ cases the deviation exceeds $\pm 6 \mathrm{~mm}$. For linear model in $<5 \%$ cases the deviations exceed $\pm 10 \mathrm{~mm}$ while for the other models it is between 5 to $10 \%$. For 00:00 UTC while the mean absolute difference for the linear model is $\sim 3.76 \mathrm{~mm}$, the BAI regional and BAI site-specific models shows deviations of $\sim 3.82 \mathrm{~mm}$. For 12:00 UTC, while the mean deviation for linear model is $3.93 \mathrm{~mm}$ that for the BAI regional and site-specific models are, respectively, $4.22 \mathrm{~mm}$ and $4.14 \mathrm{~mm}$.

Figure 9 shows the scatter plot of the day-to-day values of PW derived from GPS data at Bangalore using the sitespecific linear model, BAI regional model and BAI sitespecific model verses the corresponding values estimated from radiosonde. The mean absolute difference, correlation coefficient, slope and bias of the best-fit line are also listed 


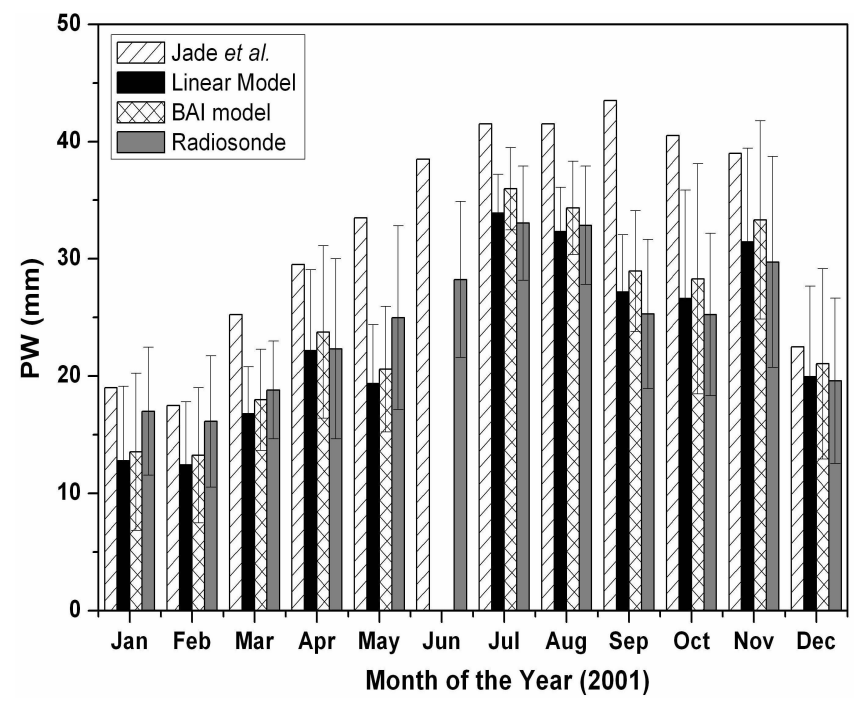

Fig. 11. Bar-chart showing a comparison of monthly mean values

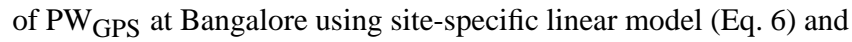
BAI regional model (Eqs. 7, 8) for the year 2001 along with corresponding values of PW derived from radiosonde data and those reported by Jade et al. (2005).

in respective frames. While the mean difference is small for 00:00 UTC, the bias is very small and the slope is more close to unity for 12:00 UTC. Examining the mean differences, it is seen that the linear model gives equally good values of $\mathrm{PW}_{\mathrm{GPS}}$, if not better, as those from BAI model which reveals that incorporation of temperature influence through $\Pi$ could not significantly improve the accuracy of PW estimation from GPS data.

To study whether these biases have been generated because of the altitude difference in the PW measurements from the GPS and the Radiosonde site, the water vapor profile from radiosonde is extrapolated using proper scaling technique to the GPS site altitude. The cumulative frequency of the deviation of GPS estimated and radiosonde estimated (after extrapolating the water vapor) PW is presented in Fig. 10. The top and the middle panel are respectively for 00:00 and 12:00 UTC and the base panel represent the composite distribution combining the data for 00:00 and 12:00 UTC. It is found that after accounting for the height difference $(\sim 100 \mathrm{~m}$ in this case) between the GPS and radiosonde sites, the mean deviation in PW is $\sim 4.0 \mathrm{~mm}$ for all the three models. While the probability of positive deviations is more for linear model, in around $35 \%$ cases the deviation exceeds $\pm 6 \mathrm{~mm}$. For linear model in $\sim 80 \%$ cases the deviations are between $\pm 2 \mathrm{~mm}$ while for the other models it is between 60 to $70 \%$.

It would be worth in this context to compare the PW estimates from different models with radiosonde derived values on a monthly mean scale. The Fig. 11 shows a bar-chart presenting the monthly mean values of PW for the year 2001, obtained from radiosonde data along with those estimated

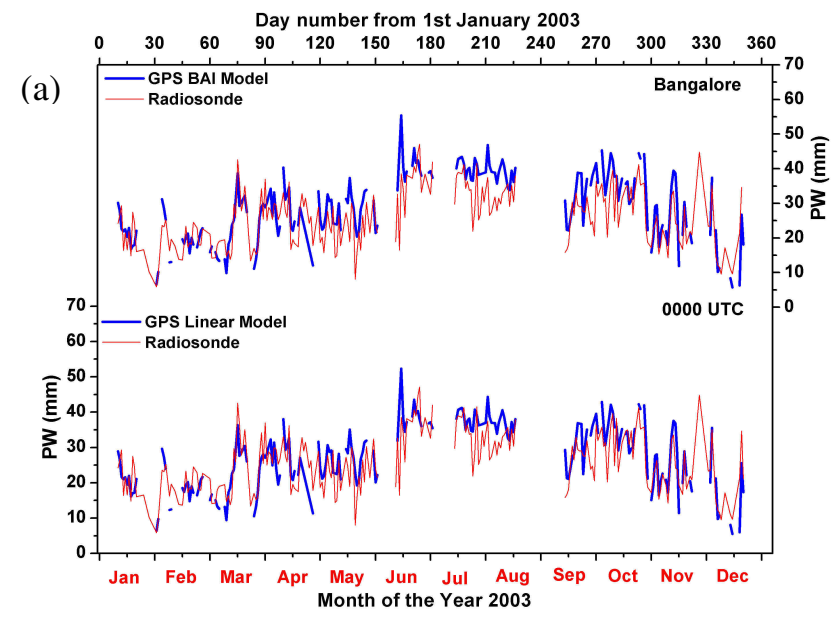

Day number from 1st January 2003

(b)

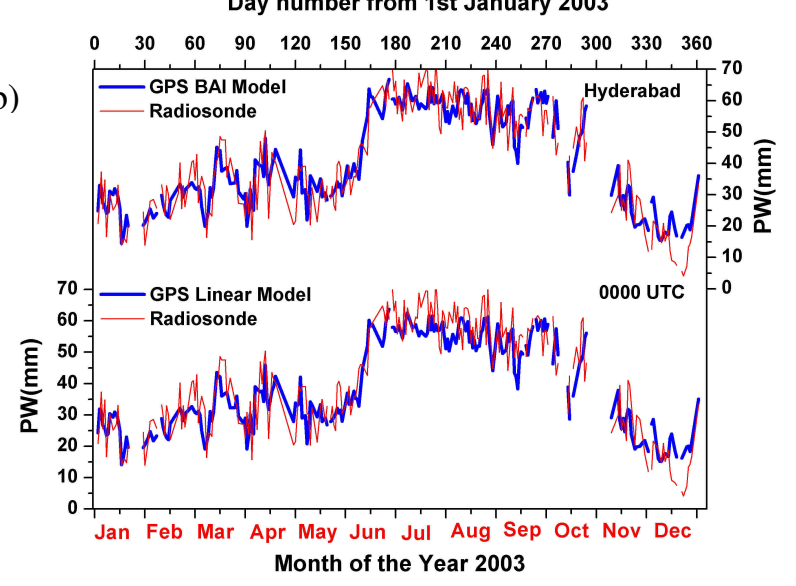

Fig. 12. Daily PW estimated from GPS data for the year 2003 using BAI regional model and site-specific linear model along with those derived from radiosonde data at 00:00 UTC, for Bangalore (a) and same for Hyderabad (b).

from GPS data employing the two models described above and those reported by Jade et al. (2005) who used the Bevis model. The seasonal variation in PW is well depicted in all the estimations. Standard deviations amounting to $\sim 10 \mathrm{~mm}$ in each month indicate large day-to-day variability. While the GPS underestimate the PW in the first half of the year (January-May), it overestimates in the later part. The deviations are $\leq 4 \mathrm{~mm}$ during the winter period and $\leq 2 \mathrm{~mm}$ during the summer/monsoon period. However, it would be worth in this context to note that typical accuracies associated with radiosonde measurements as quoted by Bisagni et al. (1989) are respectively for the barometric pressure about $\pm 2.0 \mathrm{mb}$, temperature about $\pm 0.4 \mathrm{~K}$ and for relative humidity $\pm 4 \%$. This can lead to an error of approximately $2.0 \mathrm{~mm}$ in PW estimation (Elgered, 1993).

The applicability of these models at another location over the subcontinent is examined using the GPS data from Hyderabad $\left(17.45^{\circ} \mathrm{N}\right.$ and $\left.78.46^{\circ} \mathrm{E}\right)$, a station located $5^{\circ}$ North 
of Bangalore. Though GPS data from Hyderabad is available since November 2002, good quality continuous one year data from January 2003 is used for this study. In order to accomplish a direct comparison the GPS data from Bangalore for the same period is also analysed and the results are inter-compared. Site-specific hydrostatic and non-hydrostatic delay linear regression models (similar to Eqs. 4 and 6) established for Hyderabad, yielded a value of $2.23 \pm 0.000299 \mathrm{~mm} \mathrm{mb}^{-1}$ and $0.156 \pm 0.00014$, respectively, for the proportionality constants. These models along with the $T_{m}$-based BAI model are used to retrieve the values of PW on individual days using the GPS data recorded at Hyderabad during the year 2003. The retrieved values of daily PW at the two sites are compared with those estimated from radiosonde measurements during the corresponding period. A time series plot of the retrieved PW at 00:00 UTC for the two stations in the year 2003 is presented in Fig. 12. The mean absolute difference in PW between the site-specific linear model and the radiosonde derived PW for Bangalore is $\sim 4.4 \mathrm{~mm}$ whereas that for the BAI regional and BAI sitespecific models are $\sim 5.1 \mathrm{~mm}$. This is comparable to the corresponding deviations estimated for the period 2001-2002 from Fig. 6. For Hyderabad the corresponding mean absolute difference in PW for the site-specific linear model is $\sim 5.9 \mathrm{~mm}$, and that for the BAI model is $\sim 5.2 \mathrm{~mm}$. This shows that for Hyderabad the BAI model shows a better performance compared to linear model. A quantitative comparison of GPS derived PW using these two models with that obtained from the radiosonde data on a monthly mean basis is presented in Fig. 13. The top panel in Fig. 13 shows the month-to-month PW variation estimated from GPS data employing linear model and BAI model for Bangalore for the year 2003 and base panel the same for Hyderabad. Except for a small inter annual variation the pattern in Fig. 13a compares favorably with that in Fig. 11. The annual variation of mean PW at Bangalore and Hyderabad is almost similar except for the fact that the absolute value of PW at Hyderabad is larger than that at Bangalore for the corresponding period. The mean value of $\mathrm{PW}$ at Bangalore varies from $\sim 10 \mathrm{~mm}$ (December) to $\sim 40 \mathrm{~mm}$ (July) and that at Hyderabad varies in the range of $\sim 20 \mathrm{~mm}$ (December) to $\sim 60 \mathrm{~mm}$ (July). This figure also shows that, unlike Bangalore, the performance of the BAI model for Hyderabad is better than that of the sitespecific linear model.

\section{Conclusion}

The seasonal variation of water vapor weighted mean temperature $\left(T_{m}\right)$ used in PW retrieval from GPS data is studied for eight stations over the Indian subcontinent located in the latitude range of $8^{\circ} \mathrm{N}$ to $32^{\circ} \mathrm{N}$ following the Bevis model. An empirical model for $T_{m}$ based on surface temperature adapting the Bevis model is developed for the Indian zone. Using the upper air data obtained from daily
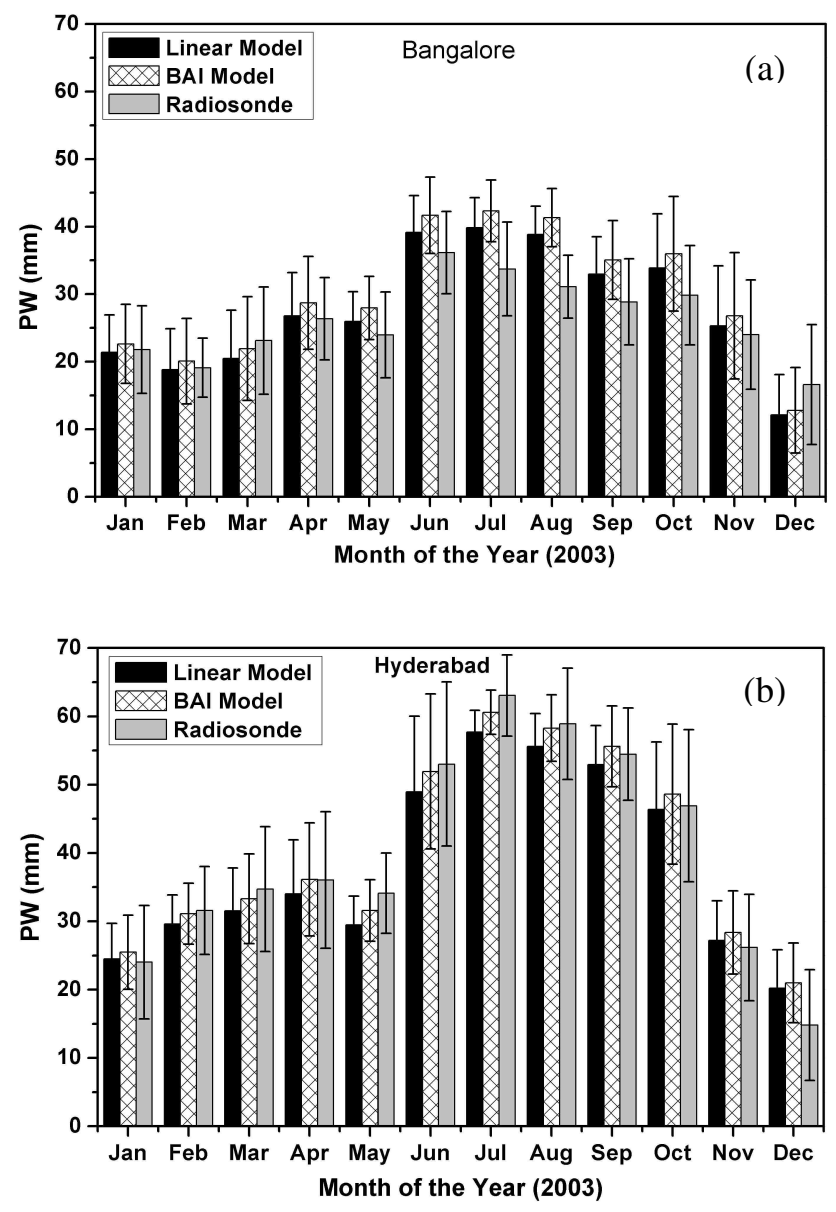

Fig. 13. The figure shows the performance of the site-specific linear and BAI regional models over two locations in Indian subcontinent. The bar-chart showing a comparison of monthly mean values of $\mathrm{PW}_{\mathrm{GPS}}$ using the temperature independent site-specific linear model (Eq. 6b) and BAI regional model (Eqs. 7, 8) for the year 2003 along with corresponding values of PW derived from radiosonde data at Bangalore (a); and same for Hyderabad (b).

radiosonde ascends for three years the dry and wet components of "true" ZTD for Bangalore are estimated theoretically using Eqs. (3a) and (3b). These are used further to establish simple site-specific linear models relating the ZHD and ZWD with ground measured atmospheric pressure and integrated water vapor parameters, respectively. The utility of these models for a tropical station is examined using the GPS data from Bangalore. A comparison of PW estimated based on the $T_{m}$-based models and the site-specific linear model shows that; (1) The simple linear model though does not make use of the effect of the variation in atmospheric temperature is well suited for PW estimation (with locally derived coefficients) for the tropical region, (2) A station specific $T_{m}$-based model is not superior to a region specific model over the tropics and (3) the seasonal variability of $\prod$ is significant for mid-latitude station. This study also shows 
that the temperature independent site-specific linear model, which behaves quite satisfactorily for the equatorial stations, is inadequate for higher latitudes and in such cases the performance of $T_{m}$-based model is better than that of the linear model.

Acknowledgements. The authors acknowledge with thanks the India Meteorology Department, Pune, for providing the radiosonde data for different RIM stations, which is used for developing the mean model and other analysis and also thank R. W. King, MIT, for providing GAMIT software. The authors also thank the anonymous reviewers for their critical comments and valuable suggestions.

Topical Editor F. D'Andrea thanks J. van Baelen and another anonymous referee for their help in evaluating this paper.

\section{References}

Askne, J. and Nordius, H.: Estimation of tropospheric delay for microwave from surface weather data, Radio Sci., 22, 379-386, 1987.

Bevis, M., Businger, S., Herring, T. A., Rocken, C., Anthes, R. A., and Ware, R. H.: GPS meteorology: Remote sensing of atmospheric water vapor using the Global Positioning system, J. Geophys. Res., 97, 15 787-15 801, 1992.

Bevis, M., Businger, S., Chiswell, S., Herring, T. A., Anthes, R., Rocken, C., and Ware, R. H.: GPS meteorology: Mapping Zenith wet delays onto precipitable water, J. Appl. Meteor., 33, 379386, 1994.

Bisagni, J. J.: Wet tropospheric calibration from daily surface and radiometric topographies in the western north atlantic, J. Geophys. Res., 94, 3247-3254, 1989.

Businger, S., Chiswell, S. R., Bevis, M., Duan, J., Anthes, R., Rocken, C., Ware, R. H., Exner, T. M., Vanhove, T., and Solheim, F.: The promise of GPS in atmospheric monitoring, B. Am. Meteor. Soc., 77, 5-18, 1996.

Davis, J. L., Herring, T. A., Sharipo, I. I., Rogers, A. E. E., and Elgered, G.: Geodesy by radio interferometry: Effects of atmospheric modeling errors on estimates of baseline length, Radio Sci., 20(6), 1593-1607, 1985.

Elgered, G.: Tropospheric radio-path delay from ground-based microwave radiometry, in: Atmospheric Remote Sensing by Microwave Radiometry, edited by: Janssen, M., John Wiley, New York, pp. 215-258, 1993.

Emardson, T. R., Elgered, G., and Johansson, J.: Three months of continuous monitoring of atmospheric water vapor with a network of GPS receivers, J. Geophys. Res., 103, 1807-1820, 1998.

Fisher, R. A.: Statistical methods for research workers, Oliver and Boyd, Edinburg, 1970.

Jade, S., Vijayan, M. S. M., Gaur, V. K., Prabhu, T. P., and Sahu, S. C.: Estimates of Precipitable water vapour from GPS data over the Indian subcontinent, J. Atmos. Solar Terr. Phys., 67, 623635, 2005.

$\mathrm{Ku}, \mathrm{H}$. H.: Notes on the use of propagation of error formulas, J. Res. Eng. Inst., NBS-C 70C(4), 263-273, 1966.
Mendes, V. B., Prates, G., Santao, L., and Langley, R. B.: An evaluation of the accuracy of models for the determination of weighted mean temperature of the atmosphere, Proc. ION 2000, National Technical Meeting, Anaheim, CA, USA, pp. 433-438, 2000.

MIT and SIO: Documentation for the GAMIT GPS analysis software, Department of Earth, Atmospheric, and Planetary Sciences, Massachusetts Institute of Technology, and Scripps Institute of Oceanography, University of California at San Diego, 2000.

Niell, A. E.: Global Mapping Functions for the atmospheric delay at radio wavelengths, J. Geophys. Res., 101, 3227-3246, 1996.

Ohtani, R. and Naito, I.: Comparisons of GPS-derived precipitable water vapors with radiosonde observations in Japan, J. Geophys. Res., 105, 26917-26929, 2000.

Rocken, C., Ware, R., Van Hove, T., Solheim, F., Alber, C., Johnson, J., Bevis, M., Chiswell, S., and Businger, S.: Sensing atmospheric water vapor with the global positioning system, Geophys. Res. Lett., 20, 2631-2634, 1993.

Rocken, C., Van Hove, T., Johnson, J., Solheim, F., Ware, R., Bevis, M., Chiswell, S., and Businger, S.: GPS/STORM - GPS sensing of atmospheric water vapor for meteorology, J. Atmos. Oceanic Technol., 12, 468-478, 1995.

Rocken, C., Van Hove, T., and Ware, R.: Near real-time GPS sensing of atmospheric water vapor, Geophys. Res. Lett., 24, 32213224, 1997.

Ross, R. J. and Rosenfeld, S.: Estimating mean weighted temperature of the atmosphere for Global Positioning System applications, J. Geophys. Res., 102(D18), 21 719-21 730, 1997.

Saastamoinen, J.: Atmospheric correction for the troposphere and stratosphere in radio ranging of satellites, in: The Use of Artificial Satellites for Geodesy, edited by: Henrikson, S. W., Mancini, A., and Chovitz, B. H., Geophysics Monograph Series, vol. 15, AGU, Washington D.C., pp. 247-251, 1972.

Saha, K., Parameswaran, K., and Suresh Raju, C.: Tropospheric delay in microwave propagation for tropical atmosphere based on data from the Indian subcontinent, J. Atmos. Solar Terr. Phys., 69, 875-905, 2007.

Schueler, T.: On Ground-Based GPS Tropospheric Delay Estimation, $\mathrm{PhD}$ thesis, Universität der Bundeswehr München, WernerHeisenberg-Weg 39, 85577 Neubiberg, 2000.

Smith, E. K. and Weintraub, S.: The constants in the equation for atmospheric refractive index at radio frequencies, Proc. IRE, 41, 1035-1037, 1953.

Solbrig, P.: Untersuchungen uber die Nutzung numerischer Wettermodelle zur Wasserdampfbestimmung mit Hilfe des Global Positioning Systems, Diploma Thesis, Institute of Geodesy and Navigation, University FAF Munich, Germany, 2000.

Suresh Raju, C., Parameswaran, K., and Korak Saha: Tropospheric Models Over Indian Subcontinent for GPS Aided GeoAugmented Navigation (GAGAN), in: Scientific Report No. SPL:SR:001:05, Space Physics Laboratory, VSSC, Trivandrum, India, 2005..

Tregoning, P., Boers, R., O'Brien, D., and Hendy, M.: Accuracy of absolute precipitable water vapor estimates from GPS observations. J. Geophys. Res., 103, 28 701-28 710, 1998. 